\title{
SÍNTESE DE CARVÕES ATIVADOS A PARTIR DO CAROÇO DO CAJÁ E SUA APLICAÇÃO NA ADSORÇÃO DA $\beta$-LACTOGLOBULINA
}

\author{
M.J.P. BRITO ${ }^{1}$; C.M.VELOSO ${ }^{2}$; R.C.F.BONOMO ${ }^{3}$; K.A.MONTEIRO ${ }^{4 *}$; T.B.SILVA ${ }^{5}$; \\ ${ }^{1}$ Universidade Estadual do Sudoeste da Bahia, Programa de Pós-Graduação em Engenharia e \\ Ciência de Alimentos \\ ${ }^{2}$ Universidade Estadual do Sudoeste da Bahia, Departamento de Ciências Naturais \\ ${ }^{3}$ Universidade Estadual do Sudoeste da Bahia, Departamento de Tecnologia Rural e Animal \\ ${ }^{4}$ Universidade Estadual do Sudoeste da Bahia, Graduação em Engenharia de Alimentos \\ ${ }^{5}$ Universidade Estadual do Sudoeste da Bahia, Graduação em Engenharia Ambiental \\ *e-mail: keivison_almeida@hotmail.com
}

\begin{abstract}
RESUMO
Diversas técnicas têm sido propostas visando à separação e purificação das proteínas do soro do leite, entre elas destaca-se o processo de adsorção. Apesar de ser um método eficiente as matrizes adsorventes comerciais utilizadas apresentam alto custo, despertando o interesse pela aplicação de adsorventes alternativos como o carvão ativado, um material adsorvente altamente poroso, que pode ser sintetizado a partir de diferentes precursores de carbono. Este trabalho teve como objetivo produzir carvões ativados utilizando como precursor de carbono o caroço do cajá e determinar a influência da variação do $\mathrm{pH}$ e da massa na eficiência de adsorção da $\beta$-lactoglobulina. Os carvões foram preparados pelo método de ativação química, utilizando o ácido fosfórico $\left(\mathrm{H}_{3} \mathrm{PO}_{4}\right)$ e hidróxido de potássio $(\mathrm{KOH})$ como agentes de ativação. Os adsorventes obtidos foram caracterizados e o rendimento do processo foi determinado. No estudo de $\mathrm{pH}$ verificou-se que o melhor desempenho do processo de adsorção foi verificado em pH 5,0, para ambos carvões, e que a massa ideal para conduzir os estudos de adsorção da proteína foi de $25 \mathrm{mg}$ para o carvão impregnado com $\mathrm{H}_{3} \mathrm{PO}_{4}$, com eficiência de $72,90 \%$, e $75 \mathrm{mg}$ para o carvão ativado com $\mathrm{KOH}$, com eficiência máxima de $67,80 \%$. Independentemente do método de ativação empregado os carvões obtidos possuem alta eficiência na adsorção da $\beta$-lactoglobulina tornando o seu uso como material adsorvente uma alternativa promissora para o fracionamento das proteínas do soro.
\end{abstract}

\section{INTRODUÇÃO}

O soro do leite, subproduto resultante da fabricação de queijos, contém uma mistura de proteínas com numerosas e diversas propriedades funcionais, possuindo muitos usos em potencial. A proteína presente em maior quantidade no soro de leite é a $\beta$ lactoglobulina $(\beta-\mathrm{Lg})$, representando cerca de $50 \%$ do total das proteínas do soro e, aproximadamente, $12 \%$ do total das proteínas presentes no leite. Suas principais 
características são: solúvel em água, globular, possuindo em sua estrutura 162 resíduos de aminoácido e massa molar aproximada de 18,3 $\mathrm{kDa}$, ponto isoelétrico igual a 5,2 e é termosensível. Essa proteína apresenta grande aplicação na indústria de alimentos, devido a sua capacidade de formação de espuma/retenção de ar, emulsificação, gelificação, ligação a aroma e sabor, formação de filmes e cápsulas protetoras (SGARBIERI, 2005; CAVALCANTI, 2010; SOUSA et al, 2011).

Diversas técnicas têm sido desenvolvidas visando à recuperação das proteínas do soro de leite, entre elas tem-se a precipitação, a ultrafiltração, sistema aquoso bifásico, cromatografia de troca iônica e a adsorção (GERBERDING; BYERS, 1998; CHEANG; ZYDNEY, 2003; CAPITANI, et al., 2005; JARA; PILOSOF, 2011).

Dentre os métodos propostos para a separação e purificação das proteínas do soro tem-se o método de adsorção, que pode ser definido uma operação de transferência de massa do tipo sólido-fluido na qual se explora a habilidade de certos sólidos em concentrar na sua superfície determinadas substâncias existentes em soluções líquidas ou gasosas, o que permite as separar dos demais componentes dessas soluções. Uma vez que os componentes se encontram adsorvidos na superfície do sólido, quanto maior for esta superfície por unidade de massa, mais favorável será a adsorção (GOMIDE, 1980).

A eficiência no processo de adsorção está diretamente ligada ao tipo de adsorvente usado. Entre os adsorventes utilizados, em diversas aplicações industriais, está o carvão ativado. $\mathrm{O}$ carvão ativado é um material com uma elevada área superficial e alta porosidade. Suas propriedades são atribuídas, essencialmente, à sua área superficial, a um bom desenvolvimento da estrutura dos poros, assim como ao tamanho dos mesmos. A distribuição dos tamanhos dos poros depende do tipo de fonte de carbono e do método de ativação empregados (TANCREDI et al., 2004; LEGROURI et al., 2005).

Apesar de ser um adsorvente bastante eficiente, o custo do carvão ativado muitas vezes restringe seu uso. Nesse sentido, existe um crescente interesse na busca de materiais alternativos de baixo custo que possam ser utilizados na sua produção. Os produtos empregados na produção de carvão são substâncias com alto valor de carbono e baixo teor de inorgânicos, assim como resíduos sólidos da agricultura, como, por exemplo, casca de coco (ANDRADE et al. 2015), caroço de azeitona e espigas de milho (IOANNIDOU et al. 2010), casca do cacau e caroço de seriguela (PEREIRA et al., 2014) entre outras matérias-primas (LI et al., 2011).

O presente trabalho teve como objetivo produzir carvões ativados, utilizando como precursor de carbono o caroço do cajá e agentes de ativação o ácido fosfórico e o hidróxido de potássio, e determinar a influência da variação do $\mathrm{pH}$ e da massa na eficiência do processo de adsorção da $\beta$ lactoglobulina.

\section{METODOLOGIA}

\subsection{Preparação do material precursor}

As matérias-primas (caroços do cajá) foram adquiridas em uma indústria de polpa de frutas situada na cidade de Coarací-Ba. Os caroços foram expostos ao sol, durante uma semana, para secagem, e em seguida triturados em moinho de facas para obtenção de partículas com tamanho entre $0,5 \mathrm{~mm}-1,70$ $\mathrm{mm}$ e, por fim, peneiradas em uma peneira de 40 mesh. O farelo obtido foi utilizado no processo de síntese dos carvões.

\subsection{Preparação dos carvões ativados}

$\mathrm{Na}$ síntese dos carvões ativados duas metodologias foram empregadas com modificação do agente de ativação. 


\subsubsection{Ativação química com ácido fosfórico - $\mathrm{H}_{3} \mathrm{PO}_{4}$}

O resíduo foi impregnado com ácido fosfórico na razão de impregnação 1:1 (massa do agente ativante/massa da caroço do cajá) e seco em estufa a $110^{\circ} \mathrm{C}$ por $24 \mathrm{~h}$. Em seguida o material foi carbonizado em forno mufla, sob fluxo de nitrogênio $\left(50 \mathrm{ml} . \mathrm{min}^{-1}\right)$ com taxa de aquecimento de $5^{\circ} \mathrm{C} \min ^{-1}$, durante $60 \mathrm{~min}$ à $450^{\circ} \mathrm{C}$. O carvão obtido foi lavado com água quente até que o $\mathrm{pH}$ neutro fosse alcançado. Em seguida, o material foi seco em estufa à $105^{\circ} \mathrm{C}$ por $24 \mathrm{~h}$ e finalmente peneirados em uma peneira de 40 mesh.

\subsubsection{Ativação química com hidróxido de potássio - KOH}

O resíduo foi impregnado com hidróxido de potássio na razão de impregnação 0,25:1 (massa do agente ativante/massa da caroço do cajá) e e seco em estufa a $110^{\circ} \mathrm{C}$ por $48 \mathrm{~h}$. A carbonização do material foi realizada em forno mufla, sob fluxo de nitrogênio (50 ml.min ${ }^{-1}$ ) com taxa de aquecimento de $5^{\circ} \mathrm{C}$ $\min ^{-1}$, durante 60 min à $450^{\circ} \mathrm{C}$. $\mathrm{O}$ material obtido foi lavado com uma solução de ácido clorídrico 0,2 mol. $\mathrm{L}^{-1}$ e levado à ebulição por um período de $30 \mathrm{~min}$ sob refluxo. Em seguida, foi lavado com água quente até atingir o pH 7,0 e seco em estufa a $105^{\circ} \mathrm{C}$ durante 24 h. Finalmente o carvão foi peneirado em uma peneira de 40 mesh.

De acordo com a etapa de processamento, os materiais utilizados foram codificados conforme descrito na Tabela 1 .

Tabela 1. Codificação das amostras obtidas durante a síntese dos carvões ativados.

\begin{tabular}{cc}
\hline Código & Material \\
\hline CAA & $\begin{array}{c}\text { Carvão ativado com ácido } \\
\text { fosfórico }\end{array}$ \\
CAH & $\begin{array}{c}\text { Carvão ativado com hidróxido } \\
\text { de potássio }\end{array}$ \\
\hline
\end{tabular}

Fonte: Autor (2015)
O rendimento do processo de síntese dos carvões, a partir dos farelos, foi calculado através da Equação 1.

$R_{c}(\%)=\left(\frac{m_{c}}{m_{p}}\right) \times 100$

Em que: $R_{c}$ é o rendimento de carvão $(\%), \mathrm{m}_{\mathrm{c}}$ é a massa do carvão obtido $(\mathrm{g})$ e $\mathrm{m}_{\mathrm{p}}$ é a massa do farelo do precursor ( $\mathrm{g}$ ).

\subsection{Caracterização dos carvões obtidos}

Os teores de umidade e cinzas dos carvões obtidos foram determinados de acordo com as normas do Instituto Adolfo Lutz (2004).

Para a determinação do ponto de carga zero dos carvões, $50 \mathrm{mg}$ da amostra de carvão foram colocadas em contato com $50,00 \mathrm{~mL}$ de soluções de cloreto de sódio $0,10 \mathrm{~mol} \mathrm{~L}^{-1} \mathrm{em}$ diferentes valores de $\mathrm{pH}$ (1-11) e deixados sobre agitação constante durante $24 \mathrm{~h}$. O pH de cada solução foi ajustado com solução de ácido clorídrico $(\mathrm{HCl})$ ou hidróxido de sódio $(\mathrm{NaOH}) 0,50 \mathrm{~mol} \mathrm{~L}^{-1}$. Ao final das $24 \mathrm{~h}$, o pH foi medido. $\mathrm{O}$ ponto de carga zero corresponde à faixa onde o $\mathrm{pH}$ final se mantém constante.

\subsection{Efeito do $\mathrm{pH}$ no processo adsortivo}

$\mathrm{O}$ pH determina a carga líquida da proteína e estudando o efeito deste parâmetro sobre o processo da adsorção, pode-se determinar a contribuição das interações eletrostáticas sobre a interação proteína/carvão ativado. Para avaliar o efeito do $\mathrm{pH}$ no processo de adsorção da $\beta$-lactoglobulina foram adicionados $10 \mathrm{mg}$ de cada carvão em tubos de ensaio contendo $5 \mathrm{~mL}$ da solução da proteína, na concentração de $500 \mathrm{mg} . \mathrm{L}^{-1}$, e o ajuste do $\mathrm{pH}$ foi realizado com adição de solução tampão fosfato de potássio $(20 \mathrm{mM})$ para $\mathrm{pH} \mathrm{7,0} \mathrm{e} \mathrm{fosfato} \mathrm{de} \mathrm{potássio} \mathrm{monobásico}$ e ácido fosfórico para o $\mathrm{pH} 3,0$ e 5,0. Os tubos foram mantidos sob agitação constante (20 rpm) à $20^{\circ} \mathrm{C}$ por $24 \mathrm{~h}$ em agitador orbital, em 
seguida foram centrifugados sendo $\mathrm{O}$ sobrenadante filtrado. A quantificação das proteínas foi realizada por leitura direta em espectrofotômetro no comprimento de onda de $280 \mathrm{~nm}$, que corresponde à presença de tirosina $(275 \mathrm{~nm})$, triptofano $(280 \mathrm{~nm})$ e fenilalanina $(260 \mathrm{~nm})$ nas moléculas (PEREIRA et al., 2014).

A partir dos valores de absorbância das soluções, lidos no espectrofotômetro e da curva de calibração, determinou-se a capacidade adsortiva de cada um dos carvões, utilizando a Equação 2.

$$
q=\frac{V C_{i n}-V C}{m_{a d s}}
$$

Em que: q é a capacidade adsortiva, após atingir o equilíbrio ( $\left.\mathrm{mg} \cdot \mathrm{g}^{-1}\right), \mathrm{V}$ é o volume de solução $(\mathrm{mL}), \mathrm{C}_{\mathrm{in}}$ concentração inicial da solução $\left(\mathrm{mg} . \mathrm{L}^{-1}\right)$, C é a concentração da solução $\left(\mathrm{mg} . \mathrm{L}^{-1}\right)$ no equilíbrio e $\mathrm{m}_{\mathrm{ads}}$ é a massa do adsorvente $(\mathrm{g})$.

A eficiência do processo adsortivo foi obtida a partir dos valores de concentração inicial e final da solução, conforme a Equação 3.

$$
\text { efic }=\left(\frac{V C_{\text {in }}-V C}{V C_{\text {in }}}\right) \times 100
$$

Em que: efic é a eficiência da adsorção $(\%), \mathrm{V}$ é o volume de solução $(\mathrm{mL}), \mathrm{C}_{\text {in }}$ concentração inicial da solução $\left(\mathrm{mg} . \mathrm{L}^{-1}\right)$ e C é a concentração da solução no equilíbrio (mg. $\mathrm{L}^{-}$ $\left.{ }^{1}\right)$.

\subsection{Análise da influência da massa de adsorvente}

Para avaliar a influência da massa de adsorvente na eficiência de adsorção, diferentes massas de cada carvão (25 mg; 50 $\mathrm{mg} ; 75 \mathrm{mg}$ ) foram adicionadas em tubos contendo $5 \mathrm{~mL}$ da solução de proteína ( $\beta$ lactoglobulina) com concentração inicial de
500 mg.L $\mathrm{L}^{-1}$ no $\mathrm{pH}$ escolhido, seguindo a mesma metodologia descrita no estudo do $\mathrm{pH}$.

\section{RESULTADO E DISCUSSÃO}

\subsection{Caracterização dos carvões obtidos}

Os resultados da caracterização química e o rendimento dos carvões obtidos estão apresentados na Tabela 2.

Tabela 2. Teor de umidade e cinzas e rendimento dos carvões obtidos.

\begin{tabular}{cccc}
\hline Amostra & $\begin{array}{c}\text { Umidade } \\
(\%)\end{array}$ & $\begin{array}{c}\text { Cinzas } \\
(\%)\end{array}$ & $\begin{array}{c}\text { Rendimento } \\
(\%)\end{array}$ \\
\hline CAA & 9,6 & 5,72 & 14,4 \\
CAH & 2,7 & 1,44 & 12,1
\end{tabular}

Fonte: Autor (2015)

Os valores de rendimento obtidos para os carvões sintetizados neste presente trabalho estão de acordo com os encontrados para carvões produzidos de outros precursores, tais como 13 a $24 \%$ para o endocarpo de café (NABAIS et al., 2008). Este parâmetro é uma é uma medida importante, uma vez que indica a viabilidade da produção do carvão ativado a partir de um dado precursor. Segundo Claudino (2003) os parâmetros importantes que irão determinar esse fator do produto carbonizado são a taxa de aquecimento, a temperatura final, o fluxo de gás de arraste e a natureza da matéria prima.

Com relação ao teor de umidade observa-se que os valores obtidos foram satisfatórios. Segundo Fernandes (2004), 10\% é o valor máximo permitido para materiais desta natureza, pois quando menor for o teor de umidade, maior a sua eficiência no processo adsortivo.

As variações na umidade, além de serem características para cada carvão, dependem ainda das condições de armazenamento e clima. Mesmo que os carvões sejam armazenados de forma adequada, isto é, hermeticamente fechados e ao abrigo da 
umidade, é praticamente impossível assegurar que os valores de umidade se mantenham constante. Adicionalmente, o total de água presente em amostras de carvão ativado é resultante da combinação entre umidade superficial e a inerente ao produto. Estudos revelam ainda, que o teor de umidade é diretamente proporcional à geração de cinzas, ou seja, quanto maior for o teor de água contido na matéria-prima, maior será a geração de cinzas (NOGUEIRA; LORA, 2003; PIZA, 2008).

O teor de cinzas de um carvão representa a quantidade de minerais presentes na biomassa utilizada como matéria prima e que não foi possível remover na etapa da lavagem após a carbonização. Os teores de cinzas encontrados para os carvões produzidos estão dentro dos valores recomendados para esse tipo de material com propriedades de adsorção eficiente, pois o ideal é que o carvão ativado apresente um teor de cinzas na faixa de 1 a 4\%. Grandes quantidades de cinzas tendem a reduzir a adsorção por bloquear a porosidade da matriz carbônica e adsorver preferencialmente água, devido a seu caráter hidrofílico (RAO, 2000; JUNIOR, 2010).

Verificou-se também que o carvão ativado com ácido fosfórico apresentou um teor de cinzas maior que o carvão ativado com hidróxido de potássio. O teor de cinzas é dependente do tipo de material precursor e do processo de síntese ao qual o carvão ativado foi submetido. Quando o carvão deriva de materiais lignocelulósicos (madeira, endocarpo de coco, caroço de pêssego, etc.), gera cinzas compostas por silicatos, aluminosilicatos e por baixas concentrações de cálcio, magnésio, ferro, potássio, sódio, zinco, chumbo, cobre e etc. Teores de cinza entre 0,2 a $9,5 \%$ são reportados na literatura para diferentes carvões derivados de materiais lignocelulósicos (ELHENDAWY et al., 2001; WEBLEY; SUN, 2010).
A determinação do $\mathrm{pH}$ de ponto de carga zero $\left(\mathrm{pH}_{\mathrm{pcz}}\right)$ foi realizada com o objetivo de investigar a carga de superfície do adsorvente. Os resultados obtidos nos ensaios do $\mathrm{pH}_{\mathrm{pcz}}$ de cada carvão foram calculados fazendo-se uma média aritmética entre os pontos que se apresentaram constantes para o $\mathrm{pH}$ final, e estão apresentados nas Figuras 1 e 2.

Figura 1. Valores de $\mathrm{pH}$ inicial e final no experimento de medida do ponto de carga zero para a amostra CAA.

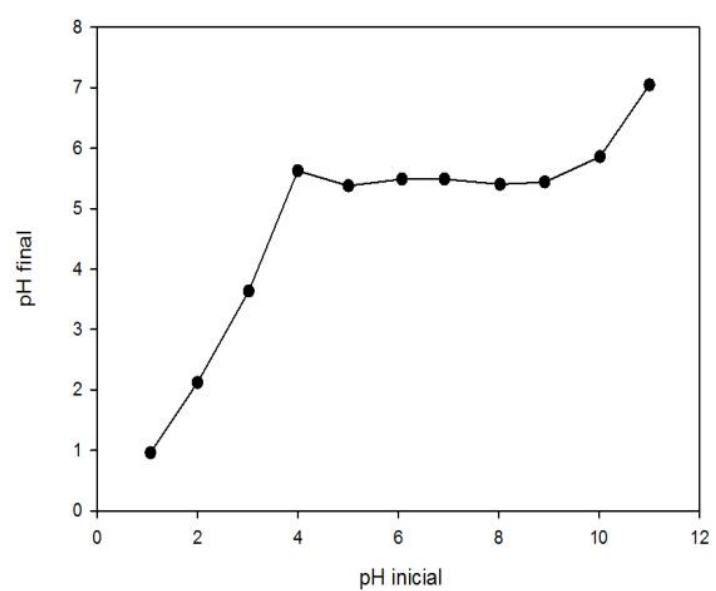

Fonte: Autor (2015)

Figura 2. Valores de $\mathrm{pH}$ inicial e final no experimento de medida do ponto de carga zero para a amostra CAH.

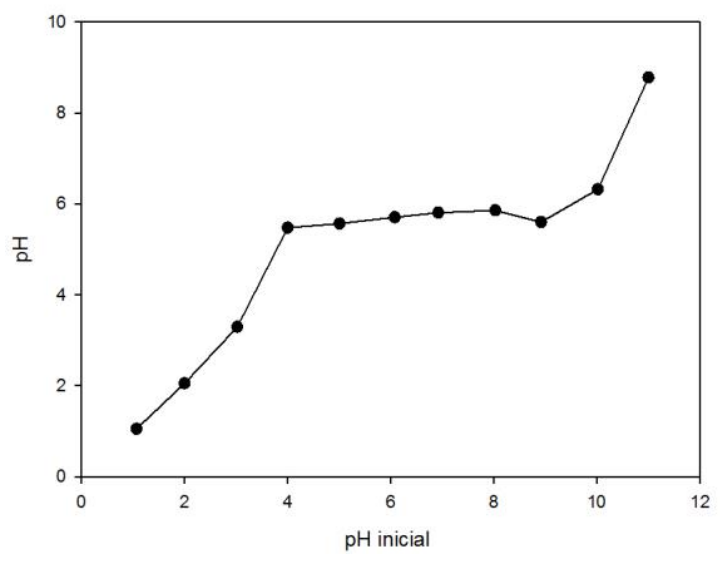

Fonte: Autor (2015) 
Os valores de $\mathrm{pH}_{\mathrm{PCZ}}$ encontrados para os carvões ativados com ácido fosfórico e hidróxido de potássio, foram, respectivamente, 5,5 e 5,6. Nestes valores, considera-se que o material atua como uma solução tampão. É possível perceber que apesar dos carvões terem sido impregnados sob diferentes condições, o $\mathrm{pH}_{\mathrm{PCZ}}$ foi semelhante, ambos apresentam propriedades notavelmente ácidas, isso pode ser explicado pela formação de grupos ácidos na superfície do carvão como resultado do método de ativação.

\subsection{Efeito do $\mathrm{pH}$ no processo adsortivo}

Os resultados obtidos para os testes adsortivos da $\beta$-lactoglobulina nas amostras dos carvões ativados, em soluções com diferentes valores de $\mathrm{pH}$ são apresentados na Tabela 3.

Tabela 3. Concentração na solução (C), capacidade adsortiva (q) e eficiência de adsorção (efic) da proteína $\beta$-lactoglobulina, com variação do $\mathrm{pH}$.

\begin{tabular}{ccccc}
\hline Amostra & $\mathrm{pH}$ & $\begin{array}{c}\mathrm{C} \\
\left(\mathrm{mg} . \mathrm{L}^{-1}\right)\end{array}$ & $\begin{array}{c}\mathrm{q} \\
\left(\mathrm{mg}^{-\mathrm{g}^{-1}}\right)\end{array}$ & $\begin{array}{c}\text { Efic } \\
(\%)\end{array}$ \\
\hline CAA & 3,0 & 470,3 & 5,9 & 5,9 \\
CAA & 5,0 & 196,7 & 60,5 & 60,6 \\
CAA & 7,0 & 563,6 & 0,0 & 0,00 \\
CAH & 3,0 & 436,6 & 12,6 & 12,6 \\
CAH & 5,0 & 175,8 & 64,6 & 64,8 \\
CAH & 7,0 & 465,0 & 7,0 & 7,0 \\
\hline
\end{tabular}

Fonte: Autor (2015)

A influência do $\mathrm{pH}$ no processo de adsorção de proteínas está associada ao ponto isoelétrico da proteína, e consequentemente à sua carga líquida em diferentes valores de $\mathrm{pH}$. A $\beta$-lactoglobulina possui ponto isoelétrico igual a 5,2 (MOOR; HA, 1993; CAVALCANTI, 2010). Como se pode observar na Tabela 3, em pH 3,0, que é menor do que o ponto isoelétrico da proteína, a eficiência da adsorção foi muito baixa para ambos os carvões. Esta adsorção é baixa, devido principalmente à repulsão electrostática entre a superfície dos carvões e das proteínas, que se encontram carregados positivamente. Para todos os carvões avaliados o $\mathrm{pH} 5,0$ se mostrou mais eficiente na adsorção da proteína indicando que o efeito hidrofóbico é que governa o processo, sendo que o carvão ativado com $\mathrm{KOH}$, apresentou melhores resultados de adsorção da $\beta$-lactoglobulina. Observou-se ainda que em pH 7,0 a eficiência decresce consideravelmente, pois nessa condição tanto a proteína quanto os adsorventes estão carregados negativamente. Para o carvão ativado com ácido fosfórico não houve adsorção. Assim, fica evidente que as interações proteína-adsorvente além de serem influenciadas por forças eletrostáticas, são também determinadas por interações hidrofóbicas e de Van der Waals (LIN et al., 2001).

Como em $\mathrm{pH}=5,0$ foram obtidos os maiores valores de capacidade adsortiva e eficiência, o mesmo foi escolhido para a realização do estudo de massa.

\subsection{Análise da influência da massa de adsorvente \\ Para avaliar o efeito da massa de} adsorvente na eficiência de adsorção, diferentes massas de carvão foram avaliadas. Os resultados desse estudo estão apresentados Tabela 4.

Observou-se que para a amostra CAA, o aumento da massa de carvão promoveu uma redução na capacidade adsortiva. Com o aumento da massa do adsorvente as forças de repulsão começam a controlar o processo de adsorção em virtude da superfície do carvão está carregada positivamente. Percebemos que com uma menor massa ( $25 \mathrm{mg}$ de carvão) obtém-se uma eficiência máxima de 72,9\%. 
Tabela 4. Concentração na solução (C), capacidade adsortiva (q) e eficiência de adsorção (efic) da proteína $\beta$-lactoglobulina, com variação da massa.

\begin{tabular}{rrrrr}
\hline Amostra & $\begin{array}{c}\text { Massa } \\
(\mathrm{mg})\end{array}$ & $\begin{array}{c}\mathrm{C} \\
\left(\mathrm{mg} . \mathrm{L}^{-1}\right)\end{array}$ & $\begin{array}{c}\mathrm{q} \\
\left(\mathrm{mg}^{-1} \mathrm{~g}^{-1}\right)\end{array}$ & $\begin{array}{c}\text { Efic } \\
(\%)\end{array}$ \\
\hline CAA & 25 & 135,5 & 72,7 & 72,9 \\
CAA & 50 & 201,8 & 29,7 & 59,6 \\
CAA & 75 & 246,0 & 16,8 & 55,8 \\
CAH & 25 & 232,4 & 53,5 & 53,5 \\
CAH & 50 & 181,9 & 31,7 & 63,6 \\
CAH & 75 & 161,0 & 22,6 & 67,8 \\
\hline
\end{tabular}

Fonte: Autor (2015)

Para a amostra CAH, a adsorção aumentou com o aumento da massa do carvão. Isto se deve ao aumento nos sítios adsortivos proporcionado pelas massas maiores do adsorvente. Comportamento semelhante foi observado por Andrade et al. (2015), ao o avaliar a influencia da massa do carvão ativado a partir do endocarpo do coco, na adsorção da $\beta$-lactoglobulina. Para o CAH a repulsão eletrostática, causada com o aumento de massa de carvão, não influenciou o processo de adsorção, demostrando que nesse caso a densidade de carga positiva na superfície do carvão pode ser menor.

\section{CONCLUSÃO}

Acerca deste estudo, pode-se concluir que o caroço do cajá pode ser utilizado como precursor para a produção de carvão ativado. Os testes adsortivos realizados demostraram que os carvões obtidos possuem alta eficiência na adsorção da $\beta$-lactoglobulina, com o emprego de uma massa relativamente pequena e uma eficiência adsortiva de $72,90 \%$ e $67,80 \%$ para o carvão ativado com ácido fosfórico e hidróxido de potássio, respectivamente, podendo ser utilizado como matriz adsorvente no fracionamento das proteínas do soro.

\section{NOMENCLATURA}

$\mathrm{C}=$ Concentração da solução no equilíbrio CAA = Carvão ativado com ácido fosfórico $\mathrm{CAH}=$ Carvão ativado com hidróxido de potássio

$\mathrm{C}_{\text {in }}=$ Concentração inicial da solução

efic $=$ Eficiência da adsorção

$\mathrm{m}_{\mathrm{ads}}=$ massa do adsorvente .

$\mathrm{m}_{\mathrm{c}}=$ Massa do carvão obtido

$\mathrm{m}_{\mathrm{p}}=$ Massa do farelo do precursor

$\mathrm{pH}_{\mathrm{PCZ}}=\mathrm{pH}$ de ponto de carga zero

$\mathrm{q}=$ Capacidade adsortiva

$\mathrm{R}_{\mathrm{c}}=$ Rendimento de carvão

$\mathrm{V}=$ Volume de solução

$\beta$-Lg $=\beta$-lactoglobulina

\section{REFERÊNCIAS}

ANDRADE, S. N.; VELOSO, C. M.; FONTAN, R. C. I. ; COSTA, R. A. S.; BRITO, M. J. P. Adsorção de $\beta$ lactoglobulina do soro de leite em carvão ativado obtido a partir do endocarpo de coco. Higiene Alimentar, v. 29, p. 4021-4025, 2015.

CAPITANI, C. D.; PACHECO, M. T. B.; GUMERATO, H. F.; VITALI, A., SCHMIDT, F. L.Recuperação de proteínas do soro de leite por meio de coacervarão com polissacarídeo. Pesquisa agropecuária brasileira, v.40, n.11, p.1123-1128, 2005.

CAVALCANTI, J.S. Recuperação e purificação de proteínas do soro de queijo "tipo Coalho" usando cromatografia de troca iônica e interação hidrofóbica em leito na forma expandida. 2010. 149p. Tese (Doutorado em Engenharia Química)Universidade Federal do Rio Grande do Norte, Natal, 2010.

CHEANG, B.; ZYDNEY, A.L. Separation of alpha-lactalbumin and beta-lactoglobulin using 
membrane ultrafiltration, Biotechnol. Bioeng, v.83, p.201-209, 2003.

CLAUDINO, A. Preparação de carvão ativado a partir de turfa e sua utilização na remoção de poluentes. 2003. 100p. Dissertação (Mestrado) - Programa de Pósgraduação em Engenharia Química da Universidade Federal de Santa Catarina, Florianópolis - SC, 2003.

EL-HENDAW. Adsorption characteristics of activated carbons obtained from corncobs. Colloids and Surfaces A: Physicochemical and Engineering Aspects, v. 180, p. 209-221, 2001.

FERNANDES, F. L. Modificações químicas em superfícies de carvões ativos de endocarpo de coco da baía e de bagaço de cana-de-açúcar visando adsorção de íon cloreto. 2004. 116 f. Dissertação - Programa de Pós-Graduação em Química, UFPB, João Pessoa, 2004.

GERBERDING, S.J.; BYERS, C.H. Preparative ion-exchange chromatography of proteins from dairy whey, J. Chromatogr. A, v.808, p.141-151, 1998.

Gomide, R. Operações Unitárias, Edição do autor, São Paulo, 1980.

INSTITUTO ADOLFO LUTZ. Normas Analíticas do Instituto Adolfo Lutz: métodos físico-químicos para análise de alimentos. $4^{\text {a }}$ edição. São Paulo, 2004.

IOANNIDOU, O.A.; ZABANIOTOU, A.A.; STAVROPOULOS, G.G.; ISLAM, M.A.; ALBANIS, T.A. Preparation of activated carbons from agricultural residues for pesticide adsorption. Chemosphere 80, 1328 1336, 2010.
JARA, F.; PILOSOF, A. M.R. Partitioning of $\alpha$-lactalbumin and $\beta$-lactoglobulin in whey protein concentrate/ hydroxypropylmethylcellulose aqueous twophase systems. Food hydrocolloids, v. 25, p. 374-380, 2011.

JUNIOR, O. F. C. Produção de Carvão Ativado a partir de Produtos Residuais de Espécies Nativas da Região Amazônica. Dissertação de Mestrado. Universidade Federal do Paraná. Paraná - PR. 73 p. 2010.

LEGROURI, K.; KHOUYA, E.; EZZINE M.; HANNACHE, H.; DENOYEL, R.; PALLIER, R.; NASLAIN R. Production of activated carbon from a new precursor molasses by activation with sulphuric acid. Journal of Hazardous Materials B. v.118 p.259 - 263, 2005.

LI, W.; YUE, Q.; GAO, B.; MA, Z.; LI, Y.; $\mathrm{ZHAO}, \mathrm{H}$. Preparation and utilization of sludge-based activated carbon for the adsorption of dyes from aqueous solutions. Chemical Engineering Journal, v.171, p. 320-327, 2011.

LIN, F. Y.; CHEN, C. S.; CHEN, W. Y.; YAMAMOTO, S. Microcalorimetric studies of interaction mechanisms between proteins and Q-Sepharose at $\mathrm{pH}$ near the isoelectric point $(\mathrm{pI})$ - effects of $\mathrm{NaCl}$ concentration, $\mathrm{pH}$ value and temperature. Journal of Chromatography A, v. 912, p. 281-289, 2001.

LIOU, T.H. Development of mesoporous structure and high adsorption capacity of biomass-based activated carbon by phosphoric acid and zinc chloride activation. Chemical Engineering Journal, v.158, p.129-142, 2010.

MOOR, C., HA, E. W. Whey protein concentrates and isolates processes and 
functional proprieties critical, Reviews in Food Science and Nutrition. Columbus, v.33, p.431-476, 1993.

NABAIS, J. M. V.; LAGINHAS, C. E; CARROTT, P. J. M.; CARROTT, M. M. L. R. Production of activated carbons from almond Shell. Fuel Processing Technology, v.92, p. 234-240, 2011.

NOGUEIRA, L. A. H.; LORA, E. E. S. Dendroenergia: fundamentos e aplicações. $2^{\mathrm{a}}$ ed. Editora Interciencia. Rio de Janeiro, 2003.

PEREIRA, R. G., VELOSO, C. M., DA SILVA, N. M., DE SOUSA, L. F., BONOMO, R. C. F., DE SOUZA, A. O., DA GUARDA, M. O \& FONTAN, R. D. C. I. Preparation of activated carbons from cocoa shells and siriguela seeds using $\mathrm{H}_{3} \mathrm{PO}{ }_{4}$ and $\mathrm{ZnCL}$ as activating agents for BSA and $\alpha$-lactalbumin adsorption. Fuel Processing Technology, v.126, p.476-486, 2014.

PIZA, A. V. T. Avaliação da capacidade adsortiva de carvões ativados para a remoção de Diuron e Hexazinona. 2008. Dissertação (Mestrado) - Centro de Ciencias Exatas Naturais e Tecnologicas da Universidade de Ribeirao Preto, Ribeirao Preto, 2008.

RAO, R.M. Production of granular activated carbons from select agricultural by-products and evaluation of their physical, chemical and adsorption properties.

Bioresource

Technology, v. 71, p. 113-123, 2000.

SGARBIERI, V. C. Review: Structural and Physicochemical Properties of Milk Proteins.

Braz. J. Food Technol, v.8, p.43-56, 2005.

SOUSA, R. C. S. ; COIMBRA, J. S. R. ; MONTEIRO, A. A. ; POLITO, T. O. S.;
OLIVEIRA, M. J. . Adsorção de $\beta$ lactoglobulina do soro de leite em hidroxiapatita: efeito do $\mathrm{pH}$ e da concentração de sal. Higiene Alimentar, v. 25, p. 14, 2011.

TANCREDI, N.; MEDERO, N.; MÖLLER, F.; PÍRIZ, J.; PLADA C.; CORDERO T. Phenol adsorption onto powdered and granular activated carbon, prepared from Eucalyptus wood. Journal of Colloid and Interface Science, v. 279 p.357-363, 2004.

WEBLEY, P.A.; SUN, Y. Preparation of activated carbons from corncob with large specific surface area by a variety of chemical activators and their application in gas storage. Chemical Engineering Journal, v.162, p. 883-892, 2010.

\section{AGRADECIMENTOS}

A Coordenação de Aperfeiçoamento de Pessoal de Nível Superior Fundo de Amparo à Pesquisa do Estado Bahia pela concessão da bolsa. 